\title{
EXPERIMENTAL STUDY ON COMPRESSION BEHAVIOR OF FIBER REINFORCED CELLULAR CONCRETE STACK BONDED MASONRY PRISMS
}

\author{
Abdur Rasheed. M, Dr. Suriya Prakash. S
}

Biography: Abdur Rasheed $\mathbf{M}$ is a Ph.D. candidate at Indian Institute of Technology

Hyderabad. His research area includes sustainable construction and development of resilient

fiber reinforced foam concrete. He completed his graduate degree in structural engineering from IIT Hyderabad and bachelor degree in civil engineering from National Institute of Technology Calicut. He also worked shortly as a structural design engineer in Zedcon Consultants Pvt. Ltd. India.

Dr. S. Suriya Prakash is currently working as an associate professor at IIT Hyderabad. Before joining IIT-H, he worked with Structural Inc. USA, a design firm in strengthening of concrete structures. He has completed his PhD from Missouri University of Science and Technology, USA. He has authored more than thirty-five peer reviewed journal papers on the behavior of reinforced concrete columns under combined loading and strengthening of structural elements with FRP composites. He is a member of ACI and ASCE, USA.

\section{ABSTRACT}

This paper presents the stress-strain behavior of structural synthetic fiber reinforced Cellular Lightweight Concrete (CLC) stack bonded prisms under axial compression. Masonry compressive strength is typically obtained by testing stack bonded prisms under compression normal to its bed joint. CLC prisms of cross sectional dimensions of $200 \mathrm{~mm}$ x $150 \mathrm{~mm}(7.87$ in. $x 5.90$ in.) with an overall height of $470 \mathrm{~mm}(1.54 \mathrm{ft})$ were cast with and without different 
1 dosages of synthetic fiber reinforcement. Polyolefin was used as a structural fiber

2 reinforcement at different volume fractions (V.F) of $0.22 \%, 0.33 \%, 0.44 \%$ and $0.55 \%$ with and

3 without micro fiber dosage of $0.02 \%$. Experimental results indicate that the presence of fibers

4 helps in the improvement of strength, stiffness and ductility of CLC stack bonded prisms under

5 compression. Test results also signifies that the hybrid fiber reinforcement provides better crack

6 bridging mechanism both at micro and macro levels when compared to only macro fibers.

7 Simple analytical models were developed for stress-strain behavior of CLC blocks and stack

8 bonded CLC prisms based on the experimental results with and without fibers under

9 compression.

11 Keywords: Analytical models; CLC Prisms; Compression; Macro/Micro Fibers; Stress-Strain

12 Curves;

\section{INTRODUCTION}

14 Usage of lightweight concrete blocks has seen a rapid growth in the recent years and is slowly replacing the conventional clay bricks in masonry construction. The usage of Cellular Lightweight Concrete (CLC) blocks gives a sustainable construction solution. The production

17 process of CLC has low carbon blueprint and uses fly ash as a major ingredient ${ }^{1}$. Production 18 of clay bricks involves use of agriculturally suitable soil as a raw material. Manufacture of a 19 hundred thousand bricks requires approximately fifty tons of firewood. Therefore, CLC can 20 provide a potential alternative to the replacement of conventional red clay burnt bricks.

21 Additional benefits of using CLC include high strength/weight ratio, improved thermal

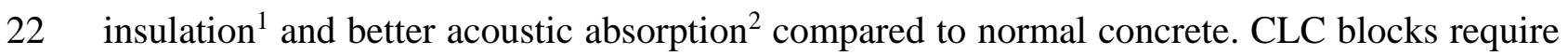
23 less number of mortar layers due to reduction in the number of joints. Therefore, CLC walls 
1 can be assembled on construction sites at a faster rate compared to the traditional clay brick

2 walls. However, the problem due to its brittle mode of failure under shear, tension and

3 compression needs to be addressed. Studies on cohesive clay and soil cement samples have

4 shown that the addition of synthetic polypropylene fibers increases the tensile and unconfined

5 compressive strength upto ten millimeter length of fiber ${ }^{3}$. It was further stated that beyond this

6 length, the strength is still increasing but at a slower rate. Addition of fibers can improve the

7 ductile behavior of CLC under shear, tensile and compression loadings making it suitable for

8 seismic applications. This improvement can be attributed to arresting of micro cracks in

9 FRCLC whereas the unreinforced specimen is observed to have crack localization in the major

10 crack plane. Micro cracks are referred to very small cracks that form in concrete but are not

11 visible to the naked eye. Major cracks have significant crack opening with width greater than

$120.2 \mathrm{~mm}$. It is worth mentioning that CLC is relatively a softer material with no coarse

13 aggregates. Its compressive modulus of elasticity is typically about one tenth of the normal

14 weight concrete. Therefore, the failure mechanism of CLC will be very different when

15 compared to the conventional concrete specimens.

16 Non-engineered unreinforced masonry (URM) buildings constitute a significant proportion

17 of the buildings around the world ${ }^{1,4,5}$. Performance evaluation and structural stability analysis

18 of URM buildings in the past revealed that URM are highly vulnerable to failure particularly

19 during seismic loading (Fig. 1). URM buildings exhibit failure mode of brittle nature when

20 subjected to lateral loads during seismic events and usually undergo complete collapse (Fig. $^{2}$

$21 \mathbf{1}^{5}$ ). Load bearing constructions are made using clay brick masonry. Infill walls made of brick

22 masonry are also commonly used as partitions in reinforced concrete and steel framed

23 structures. Both the masonry load bearing walls and infill walls were heavily damaged during

24 the past earthquakes ${ }^{6}$. Several studies in the past have focused on the behavior of URM 
1 assemblies under compression ${ }^{7-9}$. Previous experimental investigations on URM assemblies ${ }^{10-}$

$2{ }^{13}$ has shown that the brick strength of about $5 \mathrm{MPa}(0.73 \mathrm{ksi})$ is typically used in the developing

3 countries $^{10}$. Moreover, softness of these bricks cause a different state of stresses to develop

4 unlike in the case of masonry made with stiffer and stronger bricks.

6 The strength and the seismic performance of CLC structures can be improved by engineering

7 fiber reinforcement into CLC masonry system. Addition of fibers in CLC masonry can increase

8 the structural integrity by reducing permeability and leading to better durability and increased

9 life. Researchers ${ }^{14}$ in the past have reported a ductile elasto-plastic load-deflection behavior of

10 fiber reinforced cellular concrete subjected to different modes of loading. Chopped

11 polypropylene in CLC as fiber reinforcement has shown improvement in shear behavior of

12 small structural elements ${ }^{15}$. Use of micro fibers (Fibrillated) enhance the pre-cracking behavior

13 of masonry prisms by arresting cracks at the micro scale, while macro (Structural) fibers induce

14 ductile behavior in the post-peak region by arresting the structural cracks. Post-peak residual

15 strength and ductile behavior of CLC masonry can be attained by the addition of fibers.

16 However, a thorough knowledge about the behavior and the failure modes of engineered fiber

17 reinforced CLC masonry is necessary to formulate the design guidelines. The objective of this

18 study is outlined as follows. (i) To understand the stress-strain behavior of stack bonded

19 masonry prisms made of sustainable, affordable and cost effective synthetic fiber reinforced

20 CLC blocks under compression. (ii) To prove that the developed fiber reinforced CLC has

21 better performance compared to that of conventional clay brick masonry and autoclaved 22 aerated concrete (AAC) block masonry in particular under the post-peak region with a higher 23 ductility. (iii) To propose a simple design equation for CLC prisms reinforced with hybrid fiber 24 reinforcements under axial compression. 
2 The results presented in this paper are only a part of the study focusing on the subject of 3 compression behavior of stack bonded CLC masonry prisms. Flexural and tensile behavior of

4 CLC blocks was studied and reported in a companion paper by the authors ${ }^{11,16}$. CLC is 5 relatively a softer material (low stiffness) compared to the normal concrete. Therefore, macro 6 fibers are expected to significantly influence the stress-strain behavior under compression due 7 to their contribution in resisting lateral tensile stresses arising from Poisson's effect and 8 dilatancy. It is worth mentioning that no previous investigation in the past has focused on the 9 influence of synthetic structural fiber reinforcement on strength, stiffness and failure modes of 10 CLC stack bonded prisms.

\section{EXPERIMENTAL INVESTIGATION}

The scope of the experimental investigation includes the following: (i) To characterize the mechanical properties including stress-strain curves for CLC blocks, mortar and CLC prisms under compression. (ii) To study the effectiveness of synthetic fiber reinforcement on energy dissipation capacity (toughness index) and failure modes on the stress-strain behavior of fiber reinforced CLC prisms under compression. CLC blocks with varying fiber dosages were cast and tested to get stress-strain curves under compression. Mortar cylinders with cement and sand (1:6 by weight) were cast and tested under compression to obtain the bed joint stressstrain curve characteristics. Thereafter, CLC stack bonded prisms with fiber reinforced CLC blocks and normal cement mortar, were cast and the influence of varying fiber reinforcement on the composite action of masonry CLC prisms under axial compression behavior is studied. Fibers are added in the CLC masonry to provide necessary tensile and shear resistance under the action of lateral loads. The developed CLC masonry can be used as a load bearing masonry 
1 construction, which would be largely subjected to compressive stresses. The objective of

2 adding synthetic fibers was not to increase the compressive strength but more importantly to

3 improve the post-peak behavior under tension, flexure, compression and their combinations.

\section{Materials}

5 Four basic materials were used for control CLC mixture viz., 53 grade OPC (Ordinary Portland

6 Cement), siliceous type class F fly ash from National Thermal Power Corporation (NTPC),

7 potable water and sunlite foam. Lime content in class $\mathrm{F}$ flyash is typically less than $10 \%$. The

8 mix had fly ash $833 \mathrm{~kg} / \mathrm{m}^{3}\left(1404.1 \mathrm{lb} / \mathrm{yd}^{3}\right)$, cement $277 \mathrm{~kg} / \mathrm{m}^{3}\left(466.9 \mathrm{lb} / \mathrm{yd}^{3}\right)$, water $277 \mathrm{~kg} / \mathrm{m}^{3}$

$9 \quad\left(466.9 \mathrm{lb} / \mathrm{yd}^{3}\right)$ and foam $1.4 \mathrm{~kg} / \mathrm{m}^{3}\left(2.4 \mathrm{lb} / \mathrm{yd}^{3}\right)$ for a cubic meter of CLC. It is typical to use

10 water cement ratio in the range of 0.4 to 1.25 , with materials of lowest densities requiring the

11 highest ratios ${ }^{17}$. Water cement ratio of 1.0 is used in this investigation. However, fly ash is

12 expected to act as a binder as soon as the cement paste undergoes hydration process. The

13 additives are bi-component macro fiber and micro fiber (fibrillated) ${ }^{18}$ as shown in Fig. $2 \mathbf{a}$ and

14 Fig. 2b, respectively . The mechanical properties of fibers are mentioned in Table 1.

16 Details of Specimens

17 Experimental program includes testing of CLC blocks with and without fiber reinforcement, 18 mortar cylinders and CLC stack bonded prisms constructed with CLC blocks and mortar. Stack

19 bonded CLC prism with cement mortar as joints and CLC blocks with and without fiber reinforcement is shown schematically in Fig. 3. Details of the specimen and fiber dosage are shown in Table 2. 


\section{Mixing, Placing and Curing}

2 The dry raw materials such as cement and fly ash were introduced into the meta-stabilizing

3 mixer first and mixed thorough enough to ensure even distribution of the contents. Potable -

4 water was then added to the mixer until all the dry raw materials are converted to wet mix. The

5 preformed foam ${ }^{19}$ was introduced at a rate of $35 \mathrm{gm} / \mathrm{sec}$ for 40 seconds to the meta-stabilizing

6 mixer. Additional three minutes of mixing was done along with the fibers to get uniform

7 consistency and to form slurry of CLC. Thereafter, this slurry was poured into cuboidal moulds

8 of $200 \mathrm{~mm} \times 150 \mathrm{~mm}(7.87 \mathrm{in.} \times 5.90 \mathrm{in}$.) cross section and $600 \mathrm{~mm}(1.97 \mathrm{ft})$ length. Specimens

9 were demolded after 24 hours and curing was done as per IS-456 2000 (Plain and Reinforced

10 Concrete - Code of Practice [CED 2: Cement and Concrete]). At present, there are no standards

11 available for mix design of CLC using large amounts of fly ash. In this study, a large number

12 of trials were carried out to achieve a target density of $900 \pm 50 \mathrm{~kg} / \mathrm{m}^{3}$. The quantities of various

13 materials were arrived based on trial mixes. Target density of CLC was kept as $900 \pm 50 \mathrm{~kg} / \mathrm{m}^{3}$

$14\left(1517 \pm 84 \mathrm{lb} / \mathrm{yd}^{3}\right)$. Density of CLC was not much affected by the addition of fibers since the

15 specific gravity of CLC mix was in the same range as that of fibers $\left(910 \mathrm{~kg} / \mathrm{m}^{3}\left(1533.8 \mathrm{lb} / \mathrm{yd}^{3}\right)\right)$.

16 It is worth mentioning that CLC used in this study, does not have coarse and fine aggregates

17 as typical in other lightweight concretes. CLC consist of only cement, flyash and foaming agent. Studies in the past has revealed that optimum air content at which maximum strength to

19 weight ratio for foam concrete is around $40 \%^{20}$. At this air content, the density of foam concrete

20 tends to be close to $750 \mathrm{~kg} / \mathrm{m}^{3}\left(1264.2 \mathrm{lb} / \mathrm{yd}^{3}\right)$. However, for this study a total void ratio of

21 about 0.35 is used in order to achieve $900 \pm 50 \mathrm{~kg} / \mathrm{m}^{3}\left(1517 \pm 84 \mathrm{lb} / \mathrm{yd}^{3}\right)$ density. Water

22 absorption tests were carried out on CLC blocks. The water absorption was found to be 15 to

$2320 \%$, which is comparable to that of existing clay brick masonry. Stack bonded prisms were 
1 cast using blocks of $200 \times 150 \times 110$ mm (7.87 in. x 5.90 in. x 4.33 in.). Four CLC blocks were

2 used for constructing each prism. A cement mortar with cement: sand weight ratio of 1:6 and

$310 \mathrm{~mm}$ thickness was used for joints. Dimensions of the cast prism are shown in Fig. 3. After 4 curing for 28 days, compression test on CLC were carried out in displacement control mode.

\section{Test Method}

7 The quality of masonry is usually defined by its compressive strength. The American Society 8 for Testing and Materials (ASTM) provides standardized test methods for compression testing

9 of these specimen types. In terms of saving time and money during the design and construction, 10 it is desirable to ensure that the specified properties of masonry assemblages are satisfied using 11 simple and economical tests ${ }^{21}$. Testing of masonry prisms is economical and practical than 12 full-scale testing of masonry assemblages. The compressive strength of masonry is represented as $f^{\prime} \mathrm{m}$, which is specified by an engineer and used throughout masonry design procedures. This strength has upper and lower bounds governed by the specific building code adopted for construction.

16 The loading surfaces of the prisms were scraped and leveled to ensure a smooth contact area 17 prior to testing. The prisms were tested using the servo controlled compression testing machine

18 (Fig. 4). Soft capping using fiberboard was carried out to provide a flat bearing surface in order 19 to distribute the load uniformly to the specimen. Testing was stopped when the load dropped 20 by more than $30 \%$ of its maximum value. The load - displacement data were recorded through 21 a Data Acquisition (DAQ) System. Though, there exist no standards for testing fiber reinforced 22 CLC stack bonded prisms under compression, ASTM C1314 - 16 (Standard test method for 23 compressive strength of masonry prisms, 2012), IS 1905-1987 (Structural use of unreinforced 
1 masonry), and IS 3495-1992 (Parts 1-4: Methods of tests of burnt clay building brick)

2 provisions were used as a guideline to establish stress-strain curves of CLC prisms under

3 compression. Testing of prism specimen in compression was done in a servo controlled

4 compression testing machine by applying load at a rate of $0.1 \mathrm{kN} / \mathrm{sec}(0.022 \mathrm{kips} / \mathrm{sec})$ upto $70 \%$

5 of the peak load. Thereafter, the loading was applied in displacement control mode at a rate of

$60.001 \mathrm{~mm} / \mathrm{sec}\left(3.94 \times 10^{-5} \mathrm{in} . / \mathrm{sec}\right)$. The applied load was measured through load cell and

7 displacements were measured in the direction of loading using Linear Variable Displacement

8 Transducers (LVDTs) of $20 \mathrm{~mm}$ (0.78 in) stroke and $160 \mathrm{~mm}$ (6.3 in.) gauge length mounted

9 on the prisms as shown in Fig. 4.

\section{EXPERIMENTAL RESULTS AND DISCUSSION}

11 Behavior under Compression

12 CLC Blocks with Varying Fiber Dosages

13 Development of fiber reinforced CLC blocks and their behavior under flexure and compression 14 is reported in the companion paper by the authors ${ }^{11}$. The compression behavior of CLC blocks 15 is briefly explained here for comparison with the prism behavior. Strength of fiber reinforced 16 CLC blocks were obtained by testing of cylinders under compression. The peak compressive strength of CLC was found to be varying with a coefficient of variation of 10 to $15 \%$ with respect to fiber dosage. Only average stress-strain response is presented here for comparisons.

19 Unreinforced CLC cylinders subjected to compression showed a linear stress-strain behavior

20 (Fig. 5a) upto 30\% of the peak stress. Subsequently, it became nonlinear and continued up to the peak stress due to adjustment of air-voids at higher loads. Less resistance to the applied strain was observed after attaining the peak load, resulting in quite a sudden collapse of the 23 prism. 
1 The pre-cracking behavior of CLC cylinders with and without macro and hybrid fibers were

2 similar. However, there was a marginal increase in the elastic stiffness (Fig. 5a, 5b). The peak

3 strength increased with the increase in fiber dosage in both the cylinders with macro and hybrid

4 fibers. As the displacement entered the post-peak region, load drop was not observed rather the

5 post-peak load followed almost a constant value close to peak load indicating relatively less

6 degradation in post-peak stiffness. Hybrid fiber reinforcement resulted in better performance

7 compared to that of CLC cylinders with macro fibers (Fig. 5b). Hybrid-fiber reinforcement

8 showed an appreciable increase in elastic stiffness upto the peak load. However, the load

9 carrying capacity reduced in the post-peak region without undergoing much reduction in

10 stiffness (Fig. 5b). The peak load in hybrid specimens increased upto about 30\% with respect

11 to that of cylinders with only macro fibers. Compressive strength of CLC cylinders were found 12 to be in the range of 4 to $8 \mathrm{MPa}(0.58$ to $1.16 \mathrm{ksi})$.

\section{Compression Behavior of Mortar}

15 Ordinary Portland cement (OPC), conforming to IS 81121989 (Specification for 43 grade 16 ordinary Portland cement) and river sand confirming to IS: 2116-1980 (specification for sand 17 for masonry mortars) were used for the preparation of mortar cylinders. A high water-cement ratio of 0.75 was used in the casting of mortar cylinders to ensure workability. Cylinders of dimensions $200 \mathrm{~mm}$ (7.87 in.) length and $100 \mathrm{~mm}$ (3.93 in.) diameter were cast and tested under axial compression after 28 days of curing. Compressive stress-strain curves of mortar cylinders and its average behavior is shown in Fig. 6. The average behavior is arrived using a parabolic curve fit on the data scatter with and $\mathrm{R}^{2}$ value of 0.92 .

23 The deformation of specimens was measured over a gauge length of $40 \mathrm{~mm}$ (1.58 in.) with 24 the help of $20 \mathrm{~mm}$ (0.79 in.) LVDTs mounted on the specimen. Testing was carried under 
1 displacement control mode at a rate of $0.01 \mathrm{~mm} / \mathrm{sec}\left(3.94 \times 10^{-4} \mathrm{in} . / \mathrm{sec}\right)$ using servo controlled

2 compression testing machine. Test results and behavior of 1:6 mortar mix is shown in the Fig.

3 6. It is worth mentioning that the average elastic stiffness of mortar was about $17400 \mathrm{MPa}$

$4 \quad$ (2523.66 ksi) and is much higher than the stiffness of CLC blocks (about 3000 to $3500 \mathrm{MPa}$

5 (435.11 to $507.63 \mathrm{ksi})$ ). Therefore, the behavior of CLC masonry will be similar to that of low

6 stiff brick and high stiff mortar combinations in URM structures as reported by the previous

7 researchers $\left(\right.$ Prakash $^{22}$; Sarangapani et al. ${ }^{23}$; Kaushik et al. ${ }^{24}$ ).

8

\section{Behavior of CLC Prisms with and without Fiber Reinforcement}

10 A total of thirty CLC prisms was cast with different fiber dosages and tested in three series.

11 Series I was the control one with no fiber reinforcement. Series II had only macro reinforcement in the blocks whereas, the series III included various dosages of macro fibers in combination of $0.02 \%$ fixed micro fiber dosage. A minimum of three specimens was tested for each series to ensure the consistency of results. Test results of CLC stack bonded prisms in compression for all the three series of specimens are presented in Table 3. Coefficient of variation of prism strength was less than $15 \%$ and the average results are reported for comparison of the behavior of CLC prisms between hybrid fibers and macro fibers.

\section{Control CLC Prisms with No Fibers}

Stress-strain curve for the control CLC prism under axial compression exhibited a linear behavior up to $33 \%$ of the peak load (Fig. 7). Soon after the peak load was attained, the failure was quite sudden as the specimen collapsed showing almost negligible resistance to the applied strain loading. Fig. 7 shows that the strength of the unreinforced prism (3.9 $\mathrm{MPa}(0.57 \mathrm{ksi})$ ) was closer to that of block strength. The elastic modulus of the mortar (17400 MPa) was up to six times that of block (3000 MPa (435.11 ksi)). However, the elastic modulus of the prism 
1 assembly is lesser than that of both mortar and block. The elastic modulus of the prism was

$21400 \mathrm{MPa}(203.05 \mathrm{ksi}$ ) which is less than 50\% of the modulus of CLC block (3000 MPa

3 (435.11 ksi)). This is similar to combination of soft brick and high stiff mortar brick masonry

4 prisms previously studied (Prakash et al. ${ }^{22}$, Kaushik et al. ${ }^{24}$ ). This combination results in tri-

5 axial compression in blocks and bi-axial tension and uniaxial compression in mortar. The

6 failure was initiated by tension cracking in the mortar followed by its propagation as splitting

7 cracks in the CLC blocks leading to the overall failure of the prism.

\section{$8 \quad$ CLC Prisms with Macro Fibers}

9 The behavior of macro fiber reinforced prism was similar to that of unreinforced prisms until

10 the peak load with slight increase in the initial modulus of elasticity (Fig. 8a). The enhancement

11 in modulus of elasticity can be attributed to the higher stiffness contribution and much higher modulus of elasticity of fibers (around $10,000 \mathrm{MPa}(1450.38 \mathrm{ksi})$ ) compared to that of the parent CLC matrix material (around $3000 \mathrm{MPa}$ (435.11 ksi)). This increase in elastic modulus

14 is marginal due to the low volume fraction of fibers considered in the study. Fig. 8a shows the

15 improvement in the stiffness and strength of fiber reinforced prisms compared to that of 16 unreinforced prisms. The peak strength of fiber reinforced prisms lies between that of mortar and block. The stiffness of unreinforced prism was lesser than that of unreinforced block. With the addition of fiber reinforcement, the elastic modulus of the prism was improved and remained between the mortar and block modulus. As the CLC block material forms the major volume fraction of the prisms, the stress-strain behavior is closer to that of CLC blocks than mortar. The peak strength increased with the increase in fiber dosage. The post-peak region of the fiber reinforced specimen showed lesser strength degradation and higher displacement at failure. The area under the stress-strain curve (strain energy absorption) increased with increase in the fiber dosage. 
1 The behavior of macro fiber reinforced prisms $(0.22 \%$ and $0.44 \%)$ is compared with the

2 behavior of block and mortar in Fig. 8b. It was observed that the addition of high fiber dosage

3 resulted in improvement of elastic modulus of prism which is higher on comparison with the

4 control block. This can be attributed to the higher stiffness contribution and much higher

5 modulus of elasticity of fibers (around 10,000 MPa (1450.38 ksi)) compared to that of the

6 parent CLC matrix material (around $3000 \mathrm{MPa}$ (435.11 ksi)). However, even after the addition

7 of high fiber dosage, modulus of prisms (3200 MPa (464.12 ksi)) could not reach the elastic

8 modulus of mortar (17400 MPa $(2523.66 \mathrm{ksi}))$. The failure of the macro fiber reinforced prisms

9 was due to initiation of tension cracks in mortar and subsequent propagation to blocks leading

10 to splitting failure. The fibers in CLC blocks helped in resisting the cracking and contributed

11 to the post-peak load resistance. This helped to increase the displacement at failure.

\section{CLC Prisms with Hybrid Fibers}

13 Hybrid-fiber reinforced CLC prisms showed a significant increase in the elastic modulus.

14 While the softening behavior was more pronounced in the post-peak region in comparison to 15 macro fiber reinforced specimen, degradation in stiffness was lesser (Fig. 9a). Fig. 9b shows

16 the improvement in the stiffness and strength of hybrid fiber reinforced prisms compared to that of macro fiber and unreinforced prisms. The peak strength of hybrid fiber reinforced prisms was higher than the blocks and its elastic modulus was lying between the blocks and mortar. The stress-strain curves for prisms reinforced with only macro fibers and hybrid fibers are compared in Fig. 9b. The peak compressive load in hybrid fiber reinforced prisms increased when compared with CLC blocks and CLC prisms with only macro fiber reinforcement. This can be explained by the better arresting of cracks at both the micro and macro scales which led to the increase in peak compressive strength and better post-peak behavior. Post-peak behavior is improved in terms of residual load carrying capacity and compressive toughness index. Peak 
1 compressive strength of 4 to $6 \mathrm{MPa}(0.58$ to $1.16 \mathrm{ksi})$ was attained in this study similar to the

2 existing clay bricks used in developing countries. Therefore, it can be concluded that the fiber

3 reinforced CLC is a good alternative to the existing clay brick and AAC block masonry with

4 superior mechanical properties for structural applications.

\section{$5 \quad$ Failure Modes}

6 The failure mode exhibited by controls prism specimen is predominantly a single explicit crack

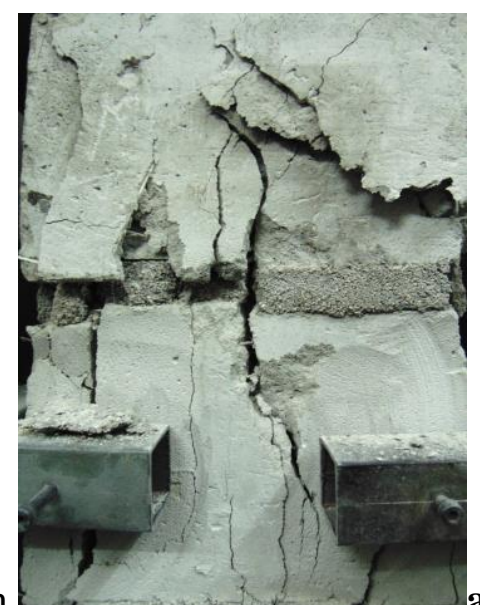

as shown in

a. Stress concentrations can be attributed to the inability

8 of distributing the stress across the cross-section of the prism. The load transfer takes place

9 largely around the crack region, leading to the faster crack propagation. On contrary to this, compression prisms with fiber reinforced cellular lightweight concrete blocks, showed a large

11 number of micro cracks
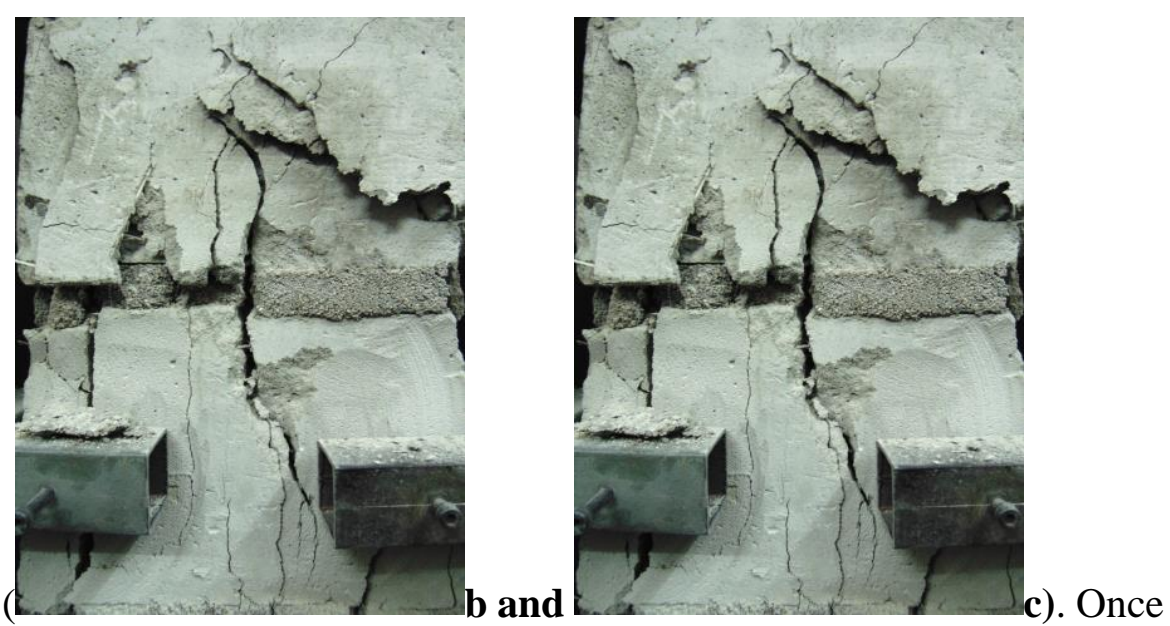

12 the matrix in CLC block is cracked, fibers gets engaged in crack arresting process as a results 
1 more number of micro cracks emerges in the material as shown in Fig. 10d. The fibers in the

2 CLC blocks formed a closed network and resisted the formation of major cracks. Elastic

3 modulus of fiber reinforced blocks was lesser than that of the mortar. This resulted in tri-axial

4 compression in CLC blocks and uniaxial compression and bi-axial tension in the mortar joint

5 which is schematically presented in Fig. 10e. Failure progression of CLC prisms was due to

6 crack initiation in mortar leading to further propagation in CLC blocks leading to overall

7 failure. Presence of fibers in the CLC blocks led to better crack resistance leading to improved

8 post-peak behavior. With the increase in load, more number of micro cracks developed along

9 the direction of loading. This indicates the possibility of stress concentration in the crack

10 region, which led to faster crack propagation. Fibers in the blocks bridged the cracks and

11 prevented its further propagation leading to lesser strength degradation with higher strains at

12 failure.

ANALYTICAL INVESTIGATION

MODELS FOR FIBER REINFORCED CLC BLOCK AND STACK BONDED PRISMS

Fiber Reinforced CLC Block

Equation for Elastic Modulus

17 The elastic modulus of the CLC $\left(\mathrm{E}_{c y}\right)$ is found to be varying with the compressive strength $\left(f_{c y}\right)$

18 as shown in Eq. 1. Equations were developed based on regression analysis based on the limited

19 test data. The goodness of fit values for all the equations lie in a range of 0.9-0.98. Microsoft

20 Excel was used for developing the equations. In order to find the variation of elastic modulus

21 with the percentage of fiber, a term called effective reinforcement index $\left(R I_{e f f}\right)$ is introduced

22 (Eq. 2). Relation between ' $\mathrm{E}_{c y}$ ' and compressive strength $\left(f_{c y}\right)$ in terms of $R I_{\text {eff }}$ can be expressed 23 as follows: 


$$
\begin{aligned}
& \mathrm{E}_{c y}=1330 \times\left(f_{c y}\right)^{0.4} \times\left(1+R I_{e f f}\right)(\mathrm{MPa}) \\
& \mathrm{E}_{c y}=600 \times\left(f_{c y}\right)^{0.4} \times\left(1+R I_{e f f}\right)(\mathrm{ksi})
\end{aligned}
$$

2 where ' $\mathrm{E}_{c y}$ ' is elastic modulus of CLC cylinder with and without fibers; ' $f_{c y}$ ' is the

3 compressive strength of cylinder; $R I=v_{f} *$ (aspect ratio) is the reinforcing index; $v_{f}$ is volume 4 fraction of fiber; aspect ratio is 1 for macro and 2.375 for micro fibers; the effective 5 reinforcement index is defined as follows:

$$
R I_{\text {eff }}=R I_{\text {macro }}\left[\frac{1}{1+2 \times R I_{\text {micro }}}\right]
$$

6

\section{$7 \quad$ Model for Stress-Strain Behavior}

8 Using the effective reinforcement index, the stress-strain model for CLC cylinders with and

9 without fiber reinforcement upto the peak can be developed as shown in Eq. 3.

$$
\begin{aligned}
& f_{c}=f_{c}^{\prime}\left(1.9 \times\left(\frac{\varepsilon_{c}}{\varepsilon_{c}^{\prime}}\right)-\left(\frac{\varepsilon_{c}}{\varepsilon_{c}^{\prime}}\right)^{2}\right) \times\left(1+R I_{e f f}\right)^{R I_{e f f}}(\mathrm{~S} . \mathrm{I} / \mathrm{U} . \mathrm{S} \text { units }) \\
& f_{c}=f_{c e}-7.7 \times\left(\varepsilon_{c}-.00243\right) \times\left[\frac{R I_{\text {micro }}}{1+R I_{\text {micro }}}\right](\mathrm{MPa}) \\
& f_{c}=f_{c e}-1.12 \times\left(\varepsilon_{c}-.00243\right) \times\left[\frac{R I_{\text {micro }}}{1+R I_{\text {micro }}}\right]_{(\mathrm{ksi})}
\end{aligned}
$$

11 In the above equations, $f_{c}$ is stress in CLC; $f_{c}$ ' is peak strength of unreinforced CLC; ' $\varepsilon_{c}$ ' is

12 strain in CLC; $\varepsilon_{c}{ }^{\prime}$ is peak strain which is taken as 0.0025 for all specimens; $R I=v_{f} \mathrm{x}$ (aspect 
1 ratio); $v_{f}$ is volume fraction of fibers; ' $f_{c e}$ ' is the compressive strength of cylinder at peak

2 strain $\varepsilon_{c}{ }^{\prime}$. The effective reinforcement index of the hybrid fiber combination is defined as per

3 Eq. 2. A straight line defined by Eq. 4 gives the post-peak behavior of the curves. Comparison

4 of predicted stress-strain behavior and experimental data for different fiber reinforcement is

5 shown in Fig. 11. Analytical Investigations using simple models have shown that the goodness

6 of fit values for all the equations lie in a range of 0.9-0.98. Therefore, the term close prediction

7 is used to describe the goodness of fit. A close prediction indicates that simple equations

8 proposed for elastic modulus and stress-strain behavior of CLC blocks with and without fiber

9 reinforcement are working well.

10

11 Fiber Reinforced CLC Prisms

12 Compressive Strength of Fiber Reinforced CLC Prisms

13 Compressive strength of fiber reinforced CLC prism can be estimated from the mortar and 14 CLC block strength as follows:

15

$$
\begin{aligned}
& f_{p}^{\prime}=\frac{f_{c y}^{1.1}}{f_{m}^{0.1}} \times\left(1+R I_{e f f}\right)^{R I_{e f f}}(\mathrm{MPa}) \\
& f_{p}^{\prime}=0.145 \times \frac{f_{c y}^{1.1}}{f_{m}^{0.1}} \times\left(1+R I_{e f f}\right)^{R I_{e f f}}(\mathrm{ksi})
\end{aligned}
$$

17 where $f_{p}$ is compressive strength of prism; $f_{m}$ is compressive strength of mortar for 1:6 grade 18 it is $6.9 \mathrm{MPa}(1.01 \mathrm{ksi}) ; f_{c y}$ is compressive strength of CLC block; $R I=v_{f} *$ aspect ratio; $v_{f}$ is 
1 volume fraction of fibers; aspect ratio is 1 for macro and 2.375 for micro; Effective fiber

2 reinforcement index $\left(R I_{e f f}\right)$ for hybrid specimens is defined as per Eq. 2.

\section{Elastic Modulus of Fiber Reinforced CLC Prisms}

5 The elastic modulus of the CLC prism with and without fibers was found to be varying with

6 the compressive strength of the prism as shown in Eq. 6. A parameter called reinforcement

7 index $(R I)$ is defined to find the variation of elastic modulus with respect to the percentage of

8 fibers. An effective reinforcement index was defined as per Eq. 2 to include the hybrid fiber

9 reinforcement combination. A relationship between modulus of elasticity $\left(\mathrm{E}_{p}\right)$ and compressive

10 strength $\left(f_{p}{ }^{\prime}\right)$ expressed as follows:

$11 \quad \mathrm{E}_{p}=40 \times\left(f_{p}^{\prime}\right)^{2.5}(\mathrm{MPa})$

$12 \quad \mathrm{E}_{p}=0.32 \times\left(f_{p}^{\prime}\right)^{2.5}$

13 where ' $\mathrm{E}_{p}$ ' is the elastic modulus of prism with and without fibers; $f_{p}$ ' is the compressive

14 strength of the prism;

15 Model for Stress-Strain Behavior of Fiber Reinforced CLC Prisms

16 The stress-strain model for prisms with and without fiber reinforcement for the pre-peak

17 behavior is defined as follows:

18

$$
f_{p}=f_{p}^{\prime}\left(1.43 \times\left(\frac{\varepsilon}{\varepsilon^{\prime}}\right)-\left(\frac{\varepsilon}{\varepsilon^{\prime}}\right)^{2}\right)
$$

19

20 The post-peak behavior can be defined using the Eq. 8 as follows. 


$$
f_{p}=f_{p} \cdot\left(\frac{0.76\left(\frac{\varepsilon}{\varepsilon^{\prime}}\right)}{1+\left(0.09\left(\frac{\varepsilon}{\varepsilon^{\prime}}\right)^{2}\right)}\right)
$$

(in S.I/U.S units)

2 where $f_{p}$ is stress in the prism with and without fibers; $f_{p}$ ' is peak strength of prism as defined

3 in Eq. 5; ' $\epsilon$ ' is strain in the prism; $\epsilon$ ' is peak strain of prisms which is taken as 0.003 .

4 Comparison of predicted stress-strain behavior of prisms with and without fibers and

5 experimental data for different fiber reinforcement is shown in Fig. 12. A close prediction

6 indicates that the simple equations proposed for elastic modulus and stress-strain behavior of

7 CLC blocks and prisms with and without fiber reinforcement are giving very close predictions

8 and hence can be used for design purposes.

\section{FURTHER RESEARCH}

10 Cost analysis indicates that the cost of fiber reinforced CLC is only $20 \%$ higher than the normal

11 CLC. Overall life-cycle analysis indicates the beneficial effects of adding fibers overweigh the

12 additional cost incurred due to fiber addition. Moreover, cheaper and cost effective fibers are

13 increasingly available in the market. Compression tests on CLC prisms constructed with mortar

14 of low strength and modulus than CLC blocks would be interesting. This combination would

15 induce tri-axial compression in mortar and bi-axial tension and uniaxial compression on the

16 CLC blocks and therefore the failure modes would be very different to what is reported in this

17 study. A study on the effect of addition of fibrillated fibers on mortar and its influence on

18 compression behavior of CLC prisms would also be interesting and is scope for further work. 
1 CLC is sustainable, light in weight and the performance of CLC can be enhanced through

2 addition of fibers for improvement in post-peak strength degradation and higher strains at

3 failure. The effect of adding synthetic fibers to CLC was studied by testing CLC stack bonded

4 prisms with various fiber dosages under compression. Based on the results present in this study,

5 the following conclusions can be drawn:

6 1. The compression behavior of composite CLC prisms was similar to that of individual

7 CLC cylinders under compression. Compressive strength of prisms increased progressively with the increase in fiber dosage. Compressive strength increased up to $28.3 \%$ for $0.55 \%$ volume fraction of macro fiber when compared to that of control prisms. Rate of increase in strength decreased with increase in fiber dosage.

2. Elastic modulus of fiber reinforced CLC blocks was lesser than that of the mortar. This resulted in tri-axial compression in CLC blocks and uniaxial compression and bi-axial tension in the mortar joint. Failure progression of CLC prisms was due to crack initiation in mortar leading to further propagation in CLC blocks leading to overall failure. Presence of fibers in the blocks led to better crack resistance and led to lesser strength and stiffness degradation when compared to control prisms.

3. Minimal change was observed in compressive strength and toughness index, when the performance of $0.44 \%$ and $0.55 \%$ volume fraction of macro fibers were compared. Hybrid fiber addition increased the compressive strength up to $45.2 \%$ for $0.44 \%$ volume fraction of macro fibers with micro fibers of $0.02 \%$ when compared to control CLC prisms.

4. Fiber reinforced CLC stack bonded prisms showed a good composite behavior under compression. This is due to the fact that the difference in strength as well as stiffness between mortar and fiber reinforced blocks reduced with increase in fiber dosage. 
1 However, peak compressive strength of the composite stack bonded prisms was closer to the low strength block due its higher volume fraction in the prism.

5. Simple equations were proposed for elastic modulus and stress-strain behavior of CLC blocks and prisms with and without fiber reinforcement. A good match was observed between the predictions and test results.

6

7

8

\section{NOTATION:}

$9 \quad \mathrm{E}_{c y}=$ elastic modulus of the CLC

$10 R I_{\text {eff }} \quad=$ Effective fiber reinforcement index

$11 f_{c y}=$ compressive strength of cylinder

$12 v_{f} \quad=$ volume fraction of fiber

$13 \varepsilon_{c}=$ strain in the cylinder

$14 \varepsilon_{c}{ }^{\prime} \quad=$ peak strain of cylinder

$15 f_{c e} \quad=$ compressive strength of cylinder at peak strain $\varepsilon_{c}{ }^{\prime}$

$16 f_{m} \quad=$ compressive strength of mortar

$17 f_{p} \quad=$ stress in the prism with and without fibers

$18 f_{p}{ }^{\prime} \quad=$ peak strength of prism

$19 \varepsilon=$ strain in the prism

$20 \varepsilon^{\prime}=$ peak strain of prisms which is taken as 0.003

$21 \quad E_{p} \quad=$ Elastic modulus of prism 
31 Zhang, B., and Poon, C. S., "Use of Furnace Bottom Ash for producing lightweight aggregate concrete with thermal insulation properties," Journal of Cleaner Production, vol. 99, 2015, pp. 94-100.

62 Narayanan, N., Jason, W., and Jan, O., “Acoustically Efficient Concretes Through Engineered Pore Structure,” ACI Materials Journal, vol. 226, 2005, pp. 135-152.

83 Estabragh, A. R., Ranjbari, S., and Javadi, A. A., "Properties of a Clay Soil and Soil Cement Reinforced with Polypropylene Fibers," ACI Materials Journal, vol. 114, 2017, pp. 195-206.

Michael L. Albert, Alaa E. Elwi, and J. J. R. C., "Strengthening of unreinforced masonry walls using FRPs," Journal of composite construction, vol. 5, 2001, pp. 76-

145 Evaluation of earthquake damaged concrete and masonry wall buildings. basic procedures manual. Applied Technology Council, Federal Emergency Management Agency (FEMA), California. Report No.: ATC-43, FEMA 306.: 1998. URM infilled RC frame buildings," Engineering Failure Analysis, vol. 33, 2013, pp. $97-118$.

W Scott McNary., and Daniel P. Abrams, M., "Mechanics of Masonry in Compression,” Journal of Structural Engineering, vol. I, 1985, pp. 857-870. elasticity of brick masonry prisms and wallettes under compression," Materials and 
Structures, 2007, pp. 241-253.

Venkatarama, B. V. R., and Vyas, C. V. U., "Influence of shear bond strength on compressive strength and stress - strain characteristics of masonry," Materials and Structures, 2008, pp. 1697-1712.

Bureau of Indian Standard(BIS), IS 1905 -1987; Structural use of unreinforced masonry (third revision), New Delhi, India.: 1987.

Rasheed, M. A., and Prakash, S. S., "Mechanical behavior of sustainable hybridsynthetic fiber reinforced cellular light weight concrete for structural applications of masonry," Construction \& Building Materials, vol. 98, 2015, pp. 631-640.

Prakash, S. S., Aqhtarudin, M., and Dhara, J. S., "Behaviour of soft brick masonry small assemblies with and without strengthening under compression loading," Materials and Structures, vol. 49, 2016, pp. 2919-2934. Using Digital Image Correlation," International Journal of Concrete Structures and Materials, vol. 10, 2016, pp. 75-85.

Zollo, R. F., and Hays, C. D., "Engineering material properties of a fiber reinforced cellular concrete," ACI Materials Journal, vol. 95, 1998, pp. 631-635. Materials Journal, vol. 172, 1997, pp. 919-934. Cellular Lightweight Concrete under Uni-axial Tension - Experimental and Analytical Studies," Construction and Building Materials, 2017. 
Journal, vol. 50, 1954, pp. 773-796.

Brugg Contec AG, Concrix-Technical Datasheet, CH-8590 Romanshorn: . Preformed Foam for Cellular Concrete 1, 1992.

Wee TH, Babu DS, Tamilselvan T, L. H., “Air-void systems of foamed concrete and its effect on mechanical properties.," ACI Materials Journal, vol. 103(1), 2006, pp. $45-52$. Masonry Society: Boulder, CO., 2008. Prakash, S. S., and Alagusundaramoorthy, P., "Load resistance of masonry wallettes and shear triplets retrofitted with GFRP composites," Journal of Cement Concrete and Composites, vol. 30, 2015, pp. 745-761. Compressive Strength," Journal of Materials in Civil Engineering, vol. 17, 2005, pp. $229-237$. Masonry under Uniaxial Compression," Journal of Materials in Civil Engineering, vol. 19, 2007, pp. 728-739.

\section{List of Tables:}

22 Table 1 - Physical and Mechanical Properties of Polyolefin Fiber

\section{Table 2 - Specimen Details}


1 Table 3 - Test Results of CLC Stack bonded prisms in Compression with and without

2 Fibers

3

4 List of Figures:

5 Fig. 1 - Common Failures of Unreinforced Masonry Systems (a) \& (b) Diagonal Cracking;

(c) Vertical Cracking at the Corner Joint; (d) Out of Plane Failure.

$7 \quad$ Fig. 2 - Details of CLC Stack bonded prism for Compression Testing

$8 \quad$ Fig. 3 - Fiber used as additives

$9 \quad$ Fig. 4 - Testing of CLC Stack bonded prisms under Compression

10 Fig. 5 - Behavior under axial compression of CLC cylinders (a) Macro fibers only (b) Hybrid 11 Fibers

Fig. 6-Stress-Strain curves for Different Samples of (a) 1:6 mortar Cylinders and (b) Average Behavior

Fig. 7 - Comparison of Typical Behavior of Control CLC Prism with Mortar and Block

Fig. 8 - Behavior of CLC Stack bonded prisms under Axial compression with (a) Macro fibers and (b) Comparison of Macro Fiber Reinforced Prism vs Control CLC Block and Mortar

Fig. 9 - Behavior of CLC Stack bonded prisms under Axial Compression (a) Hybrid Fibers and (b) Performance of Hybrid vs Macro fiber Reinforced Prisms and Control CLC and Mortar

Fig. 10 - Failure of Stack bonded prisms under Compression with and without Fibers

Fig. 11 - Comparison of Stress-Strain Curve Predictions with Test Results of Fiber Reinforced CLC Cylinders

Fig. 12 - Comparison of Analytical Stress-Strain Curve Predictions with Experimental Test 


\section{Table 1-Physical and mechanical properties of Polyolefin fiber}

\begin{tabular}{ccc}
\hline \hline & Macro Fiber & Fibrillated Fiber \\
\hline \hline Specification & Bi-component fiber & Interlinked fiber \\
\hline Form & Structural fiber & Fibrillated fiber \\
\hline Specific Gravity & 0.91 & 0.91 \\
\hline Tensile strength & $618 \mathrm{~N} / \mathrm{mm}^{2}(89.64 \mathrm{ksi})$ & $400 \mathrm{~N} / \mathrm{mm}^{2}(58.02 \mathrm{ksi})$ \\
\hline Diameter & $0.5 \mathrm{~mm}(1 / 51 \mathrm{in})$. & $0.08 \mathrm{~mm}(1 / 316 \mathrm{in})$. \\
\hline Length & $50 \mathrm{~mm}(1.97 \mathrm{in})$. & $19 \mathrm{~mm}(3 / 4 \mathrm{in})$. \\
\hline Modulus of Elasticity & $10 \mathrm{GPa}(1450.38 \mathrm{ksi})$ & $4.9 \mathrm{GPa}(710.69 \mathrm{ksi})$ \\
\hline Aspect Ratio & 100 & 237.5 \\
\hline \hline
\end{tabular}

11 Table 2-Specimen Details

\begin{tabular}{|c|c|c|c|c|}
\hline Type of Specimen & Series & Specimen Name & $\begin{array}{l}\text { Number of } \\
\text { Specimen }\end{array}$ & $\begin{array}{l}\text { Volume Fraction } \\
\text { (Macro + Micro) \% }\end{array}$ \\
\hline \multirow{9}{*}{ CLC Brick Blocks } & $\mathrm{I}$ & Control & 5 & 0 \\
\hline & \multirow{4}{*}{$\begin{array}{c}\text { II } \\
\text { (only Macro) }\end{array}$} & ma-0.22-mi-0.0 & 5 & $0.22+0.00$ \\
\hline & & ma-0.33-mi-0.0 & 5 & $0.33+0.00$ \\
\hline & & ma-0.44-mi-0.0 & 5 & $0.44+0.00$ \\
\hline & & ma-0.55-mi-0.0 & 5 & $0.55+0.00$ \\
\hline & \multirow{4}{*}{$\begin{array}{c}\text { III } \\
\text { Hybrid= } \\
\text { Macro + Micro) }\end{array}$} & ma-0.11-mi-0.02 & 5 & $0.22+0.02$ \\
\hline & & ma-0.22-mi-0.02 & 5 & $0.22+0.02$ \\
\hline & & ma-0.33-mi-0.02 & 5 & $0.33+0.02$ \\
\hline & & ma-0.44-mi-0.02 & 5 & $0.44+0.02$ \\
\hline Cement Mortar & Cement :Sand (1:6) & 1:6 Mortar Cylinder & 3 & 0 \\
\hline \multirow{9}{*}{$\begin{array}{c}\text { CLC } \\
\text { Stack bonded } \\
\text { prisms }\end{array}$} & I & Control & 3 & 0 \\
\hline & \multirow{4}{*}{$\begin{array}{c}\text { II } \\
\text { (only Macro) }\end{array}$} & ma-0.22-mi-0.0 & 3 & $0.22+0.00$ \\
\hline & & ma-0.33-mi- 0.0 & 3 & $0.33+0.00$ \\
\hline & & ma-0.44-mi-0.0 & 3 & $0.44+0.00$ \\
\hline & & ma-0.55-mi-0.0 & 3 & $0.55+0.00$ \\
\hline & \multirow{4}{*}{$\begin{array}{c}\text { III } \\
\text { Hybrid= } \\
\text { Macro + Micro) }\end{array}$} & ma-0.11-mi-0.02 & 3 & $0.22+0.02$ \\
\hline & & ma-0.22-mi-0.02 & 3 & $0.22+0.02$ \\
\hline & & ma-0.33-mi-0.02 & 3 & $0.33+0.02$ \\
\hline & & ma-0.44-mi-0.02 & 3 & $0.44+0.02$ \\
\hline
\end{tabular}

12 
1 Table 3-Test Results of CLC Stack bonded prisms in Compression with and without 2 Fibers

\begin{tabular}{|c|c|c|c|c|c|c|c|}
\hline \multirow{2}{*}{ Series } & \multirow{2}{*}{ Specimen } & \multicolumn{3}{|c|}{$\begin{array}{c}\text { Peak Compressive strength, } \mathrm{MPa} \text {. } \\
(\mathrm{ksi})\end{array}$} & \multirow{2}{*}{$\begin{array}{c}\text { Mean } \\
\text { Strength } \\
\text { 'f'm', } \\
\text { MPa. (ksi) }\end{array}$} & \multirow{2}{*}{$\begin{array}{c}\text { Co-eff. } \\
\text { of } \\
\text { Variation } \\
(\%)\end{array}$} & \multirow{2}{*}{$\begin{array}{c}\text { CTI } \\
(10-3)\end{array}$} \\
\hline & & 1 & 2 & 3 & & & \\
\hline $\mathrm{I}$ & Control & $4.11(0.56)$ & $3.78(0.55)$ & - & $3.87(0.56)$ & 5.9 & 14.69 \\
\hline \multirow{4}{*}{$\begin{array}{c}\text { II } \\
\text { (only macro) }\end{array}$} & ma-0.22-mi-0.0 & $4.40(0.64)$ & $3.73(0.54)$ & $4.03(0.58)$ & $4.05(0.58)$ & 8.1 & 29.00 \\
\hline & ma-0.33-mi-0.0 & $4.73(0.68)$ & $4.02(0.58)$ & $5.21(0.75)$ & $4.73(0.68)$ & 12.9 & 36.68 \\
\hline & ma-0.44-mi-0.0 & $4.99(0.72)$ & $5.37(0.78)$ & $4.69(0.68)$ & $5.04(0.73)$ & 6.7 & 42.43 \\
\hline & ma-0.55-mi-0.0 & $5.66(0.82)$ & $4.26(0.62)$ & $4.89(0.71)$ & $4.96(0.72)$ & 13.9 & 42.72 \\
\hline \multirow{4}{*}{ III (hybrid) } & ma-0.11-mi-0.02 & $3.77(0.55)$ & $3.38(0.49)$ & $4.87(0.70)$ & $4.00(0.58)$ & 15.7 & 28.57 \\
\hline & ma-0.22-mi-0.02 & $4.18(0.61)$ & $4.29(0.62)$ & $4.20(0.61)$ & $4.23(0.61)$ & 1.9 & 32.93 \\
\hline & ma-0.33-mi-0.02 & $5.18(0.75)$ & $5.43(0.79)$ & $3.86(0.60)$ & $4.85(0.70)$ & 17.3 & 39.28 \\
\hline & ma-0.44-mi-0.02 & $6.34(0.92)$ & $4.52(0.66)$ & $5.99(0.87)$ & $5.62(0.81)$ & 14.9 & 44.24 \\
\hline
\end{tabular}

3 CTI $^{*}$-Compressive Toughness Index

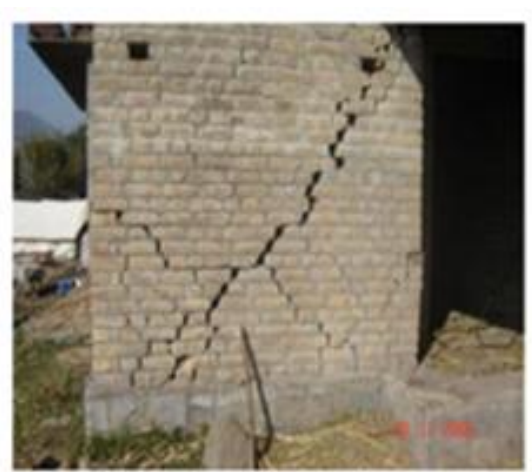

(a)

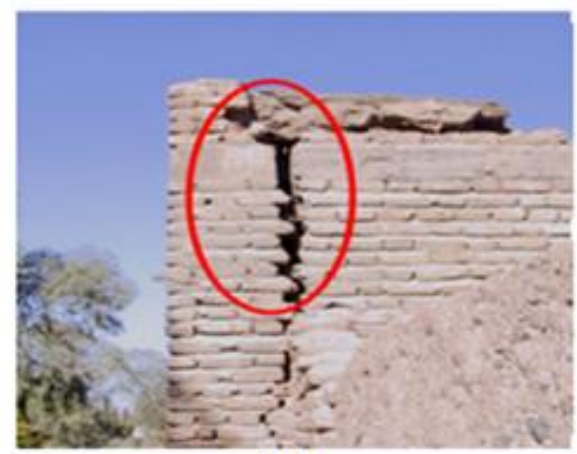

(c)

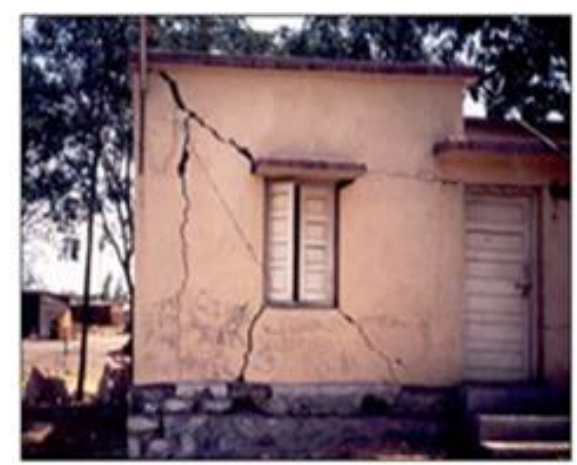

(b)

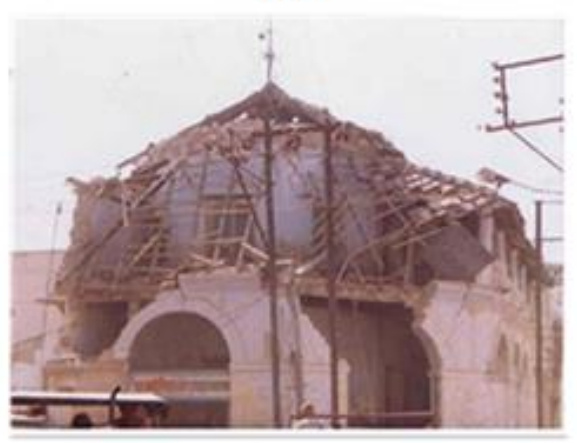

(d)

5 Fig. 1-Common Failures of Unreinforced Masonry Systems (a) \& (b) Diagonal Cracking; (c)

$6 \quad$ Vertical Cracking at the Corner Joint; (d) Out of Plane Failure 

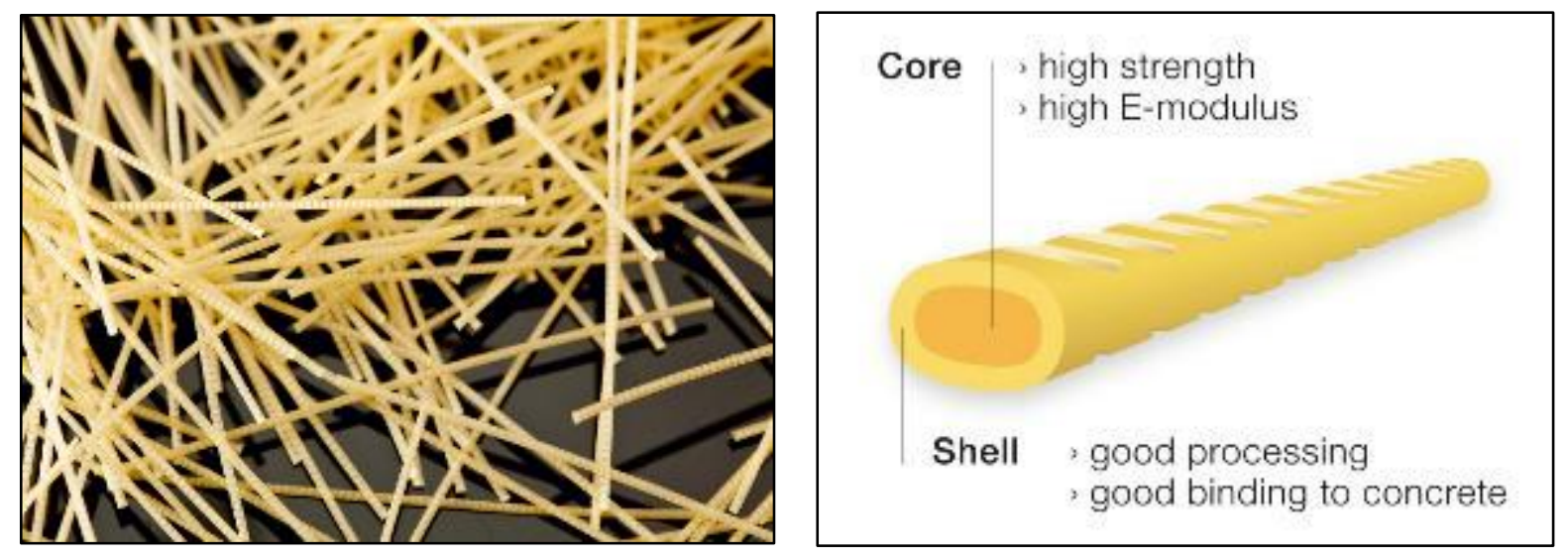

(a) Polyolefin Macro fiber
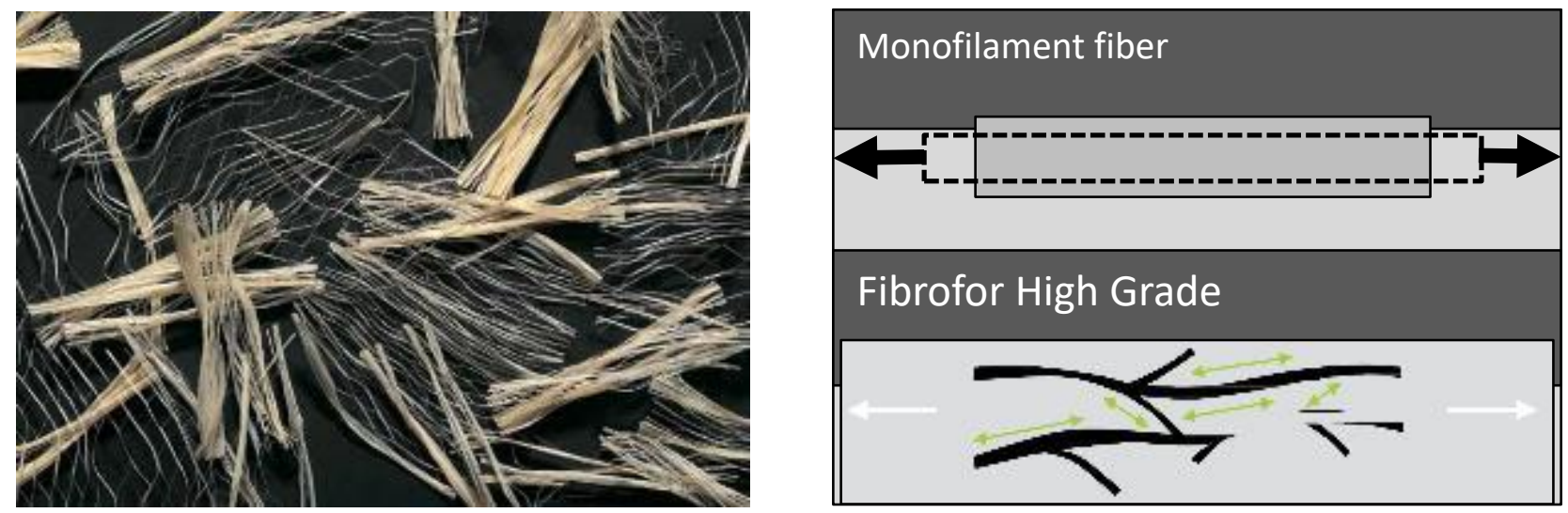

(b) Polyolefin Fibrillated Fiber

Fig. 2-Fibers used as additives

2 


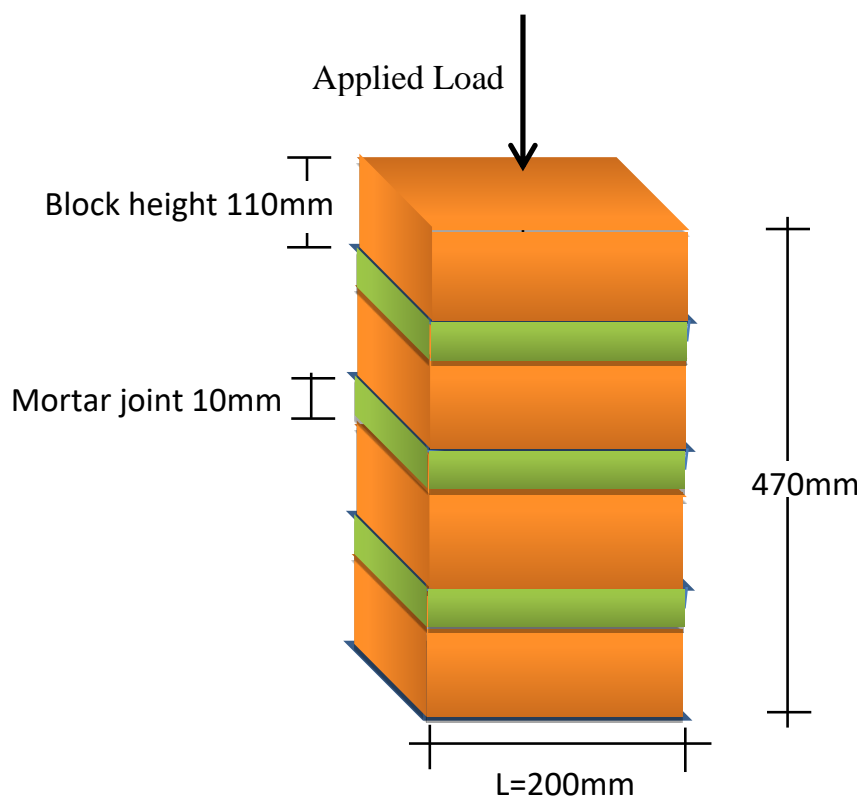

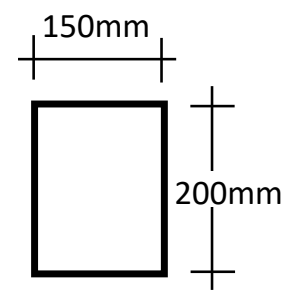

Plan Details

2 Fig. 3-Details of CLC Stack bonded prism for Compression Testing

3

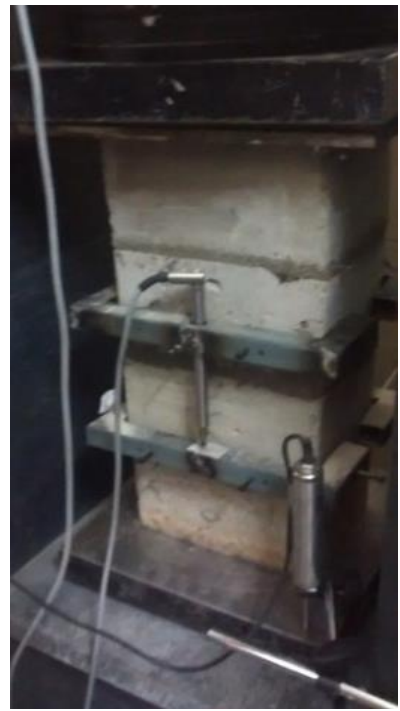

(b) CLC Prism and Instrumentation

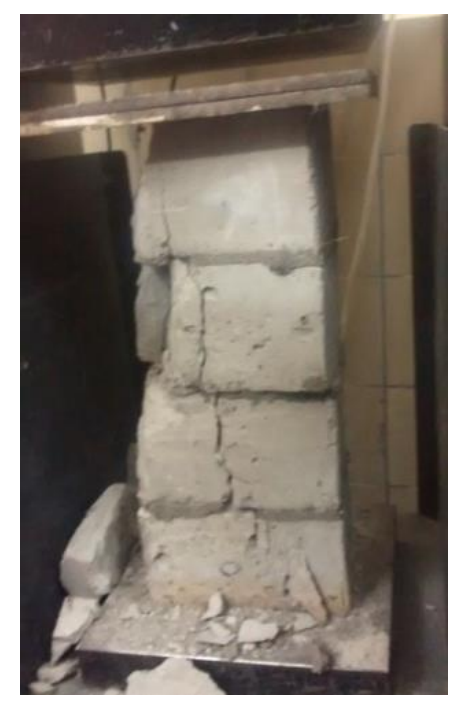

(c) Specimen after Compression Failure

Fig. 4-Testing of CLC Stack bonded prisms under Compression 


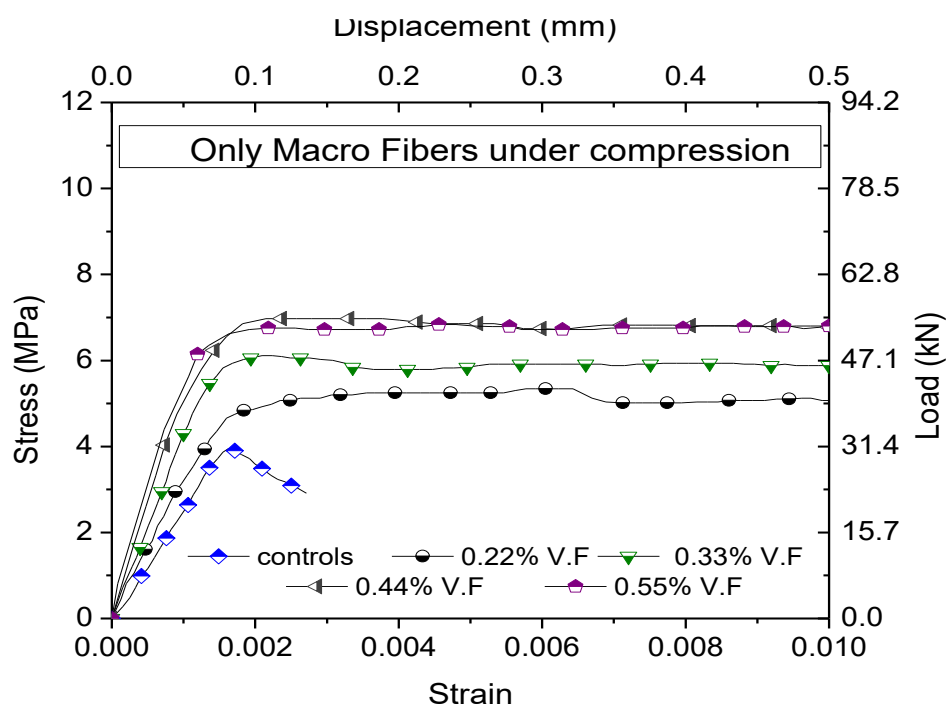

(a)

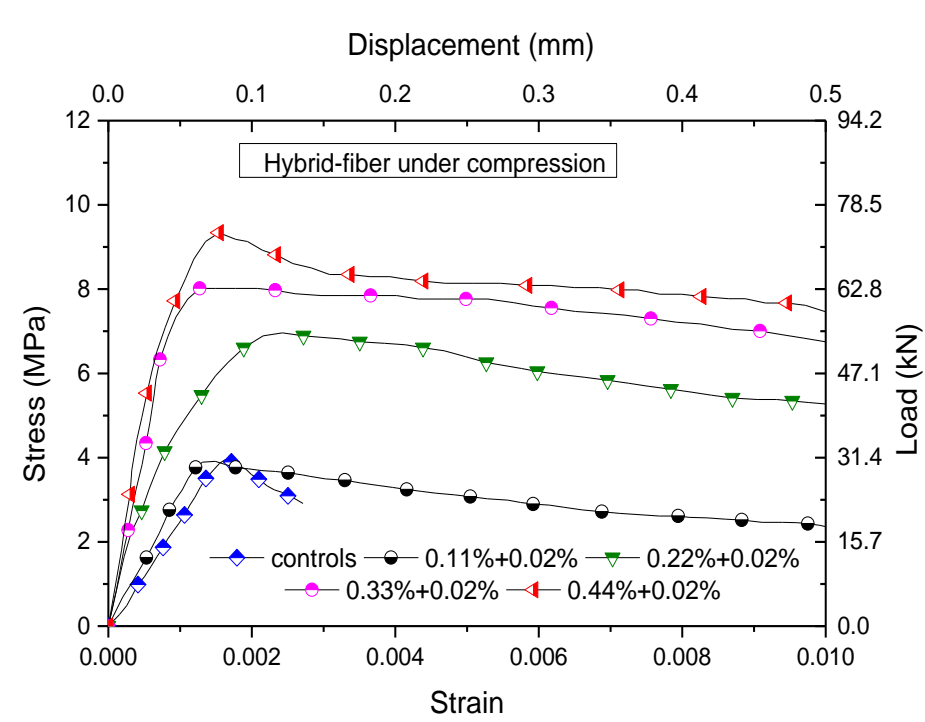

(b)

1 Fig. 5-Behavior under axial compression of CLC cylinders (a) Macro fibers only (b) Hybrid 2 Fibers $(1 \mathrm{ksi}=7 \mathrm{MPa} ; 1 \mathrm{kip}=4.4 \mathrm{kN} ; 1$ in. $=25.4 \mathrm{~mm})$

3
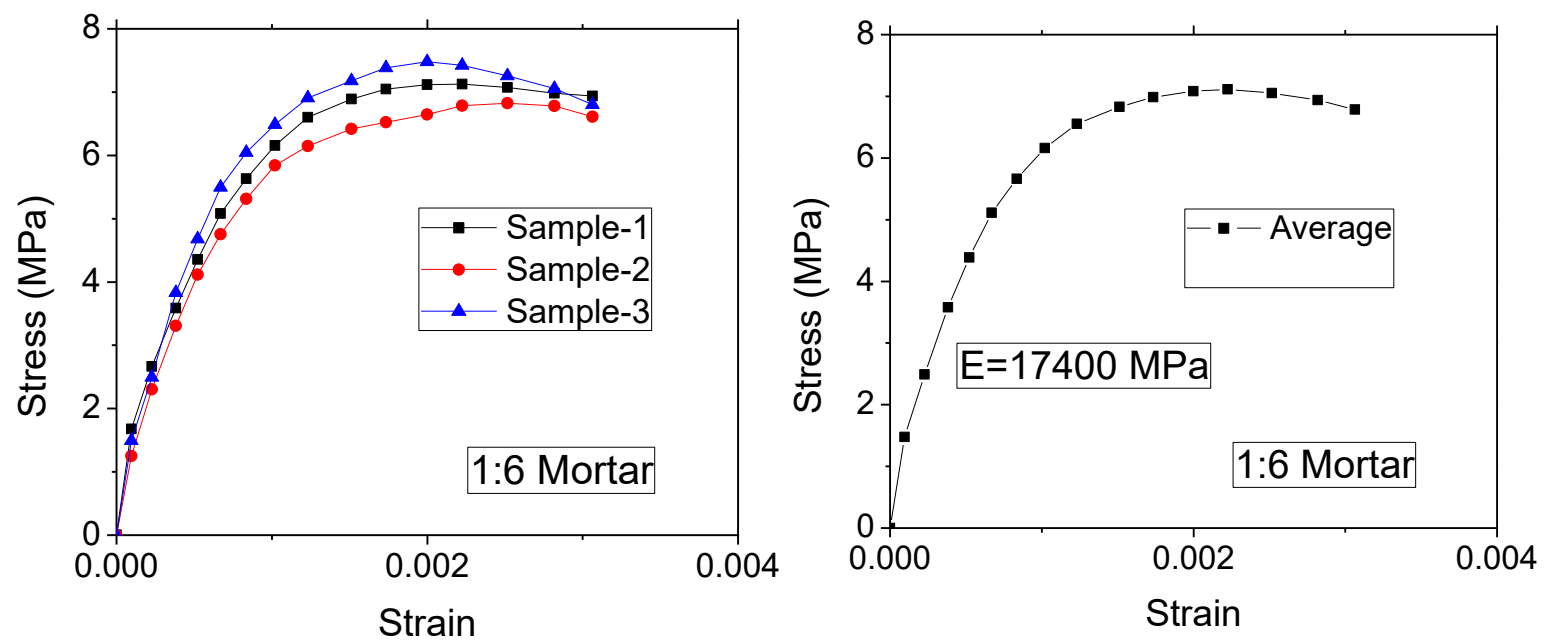

4

5 Fig. 6-Stress-Strain curves for Different Samples of (a) 1:6 mortar Cylinders and (b)

6 Average Behavior $(1 \mathrm{ksi}=7 \mathrm{MPa} ; 1 \mathrm{kip}=4.4 \mathrm{kN} ; 1$ in. $=25.4 \mathrm{~mm})$ 


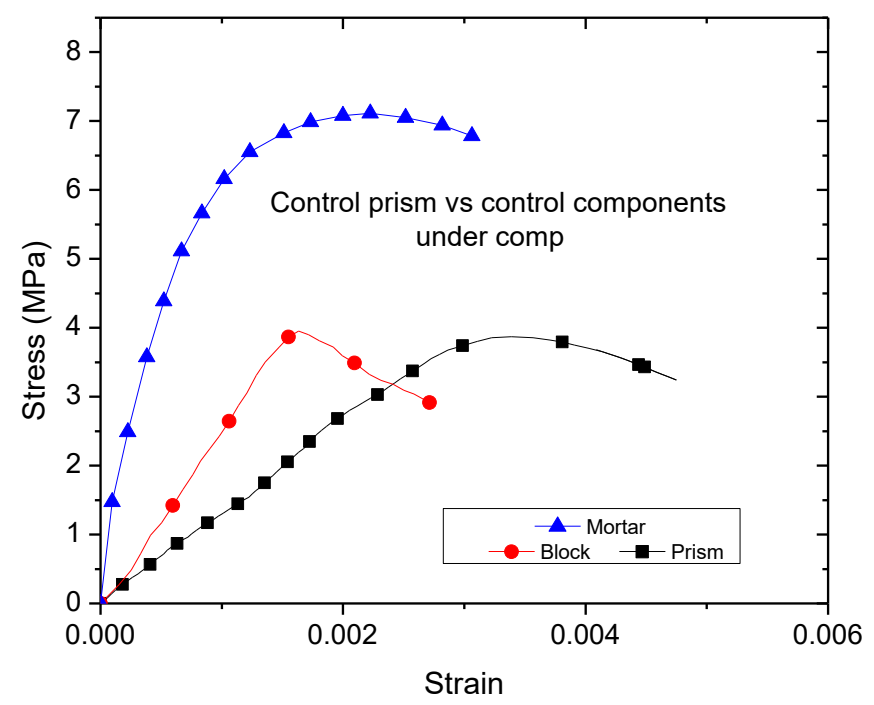

1

2 Fig. 7-Comparison of Typical Behavior of Control CLC Prism with Mortar and Block

$3 \quad(1 \mathrm{ksi}=7 \mathrm{MPa} ; 1 \mathrm{kip}=4.4 \mathrm{kN} ; 1$ in. $=25.4 \mathrm{~mm})$

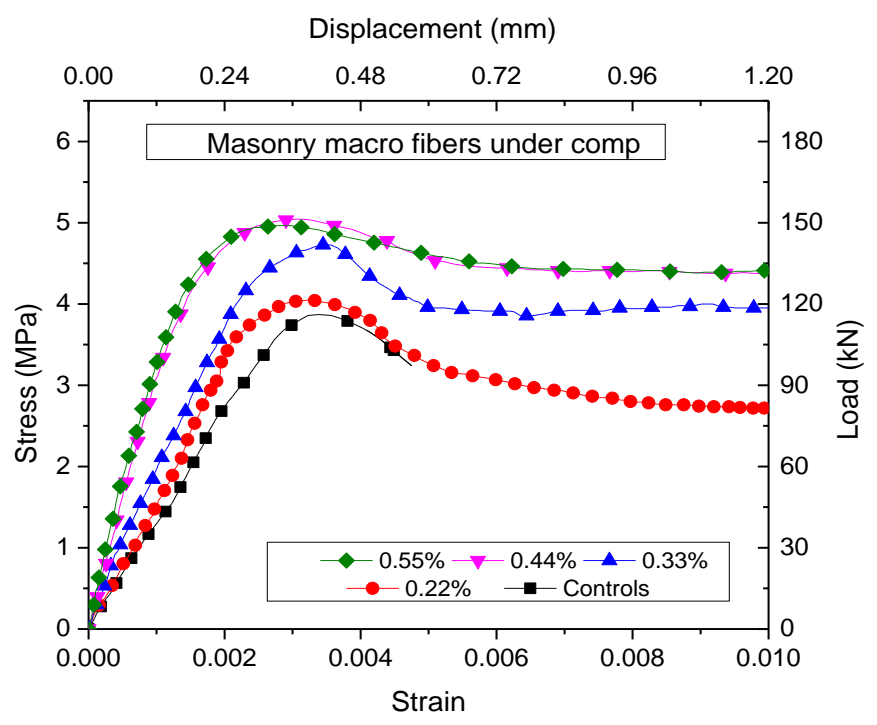

(a)

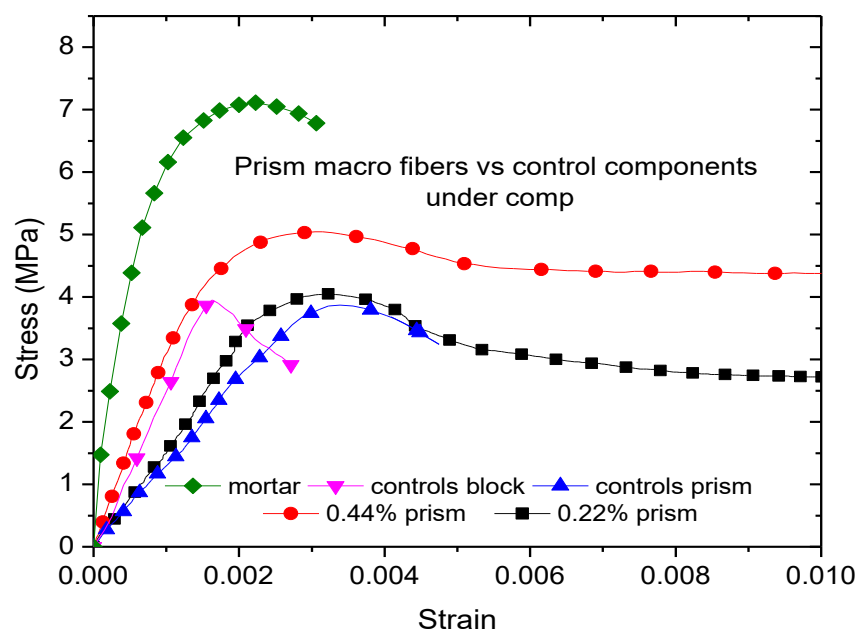

(b)

4 Fig. 8-Behavior of CLC Stack bonded prisms under Axial compression with (a) Macro fibers

5 and (b) Comparison of Macro Fiber Reinforced Prism vs Control CLC Block and Mortar

$6 \quad(1 \mathrm{ksi}=7 \mathrm{MPa} ; 1 \mathrm{kip}=4.4 \mathrm{kN} ; 1$ in. $=25.4 \mathrm{~mm})$ 


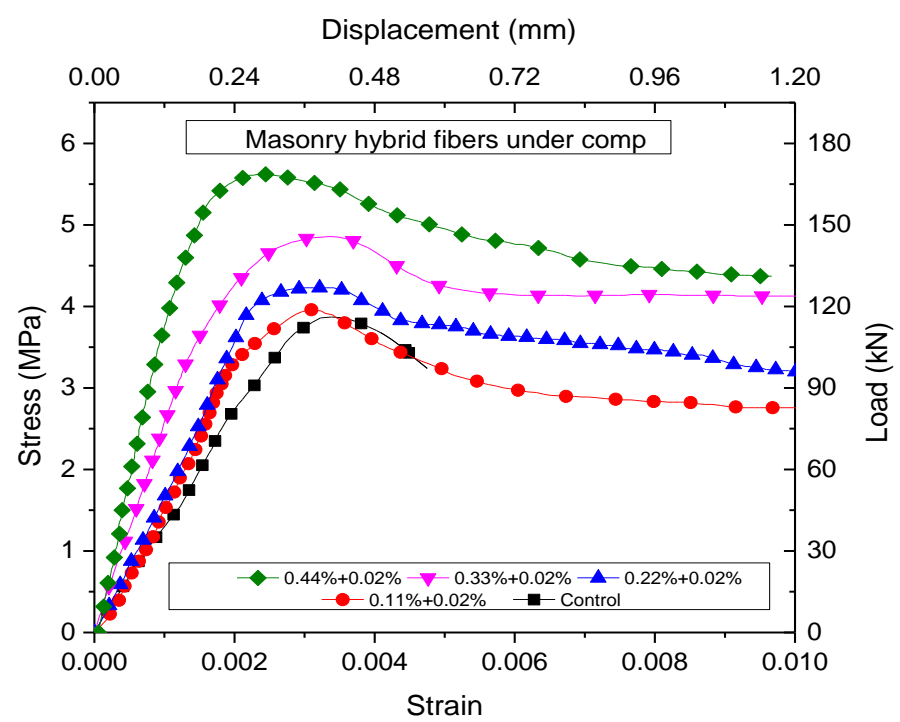

(a)
Prism hybrid vs macro fibers vs control components under comp

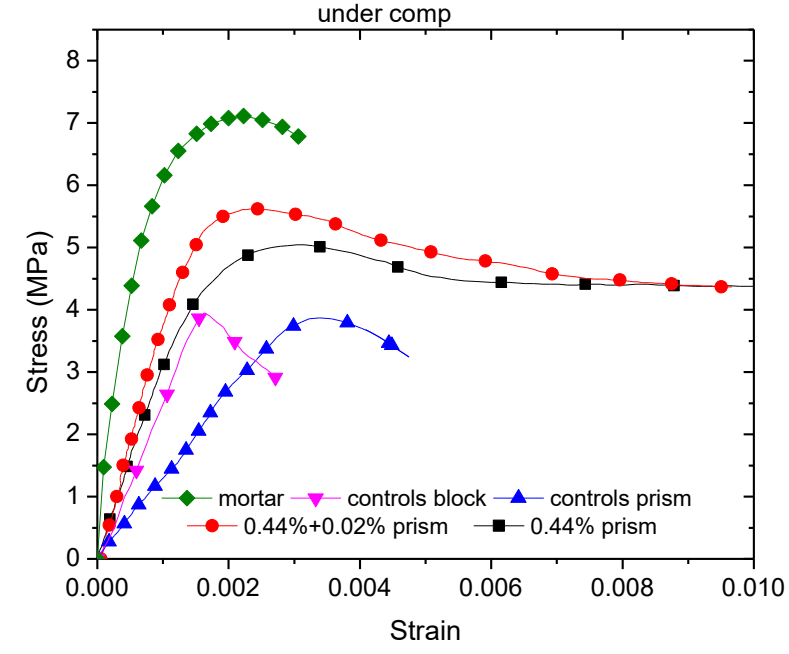

(b)

1 Fig. 9-Behavior of CLC Stack bonded prisms under Axial Compression (a) Hybrid Fibers 2 and (b) Performance of Hybrid vs Macro fiber Reinforced Prisms and Control CLC and $3 \quad$ Mortar $\quad(1 \mathrm{ksi}=7 \mathrm{MPa} ; 1 \mathrm{kip}=4.4 \mathrm{kN} ; 1$ in. $=25.4 \mathrm{~mm})$ 


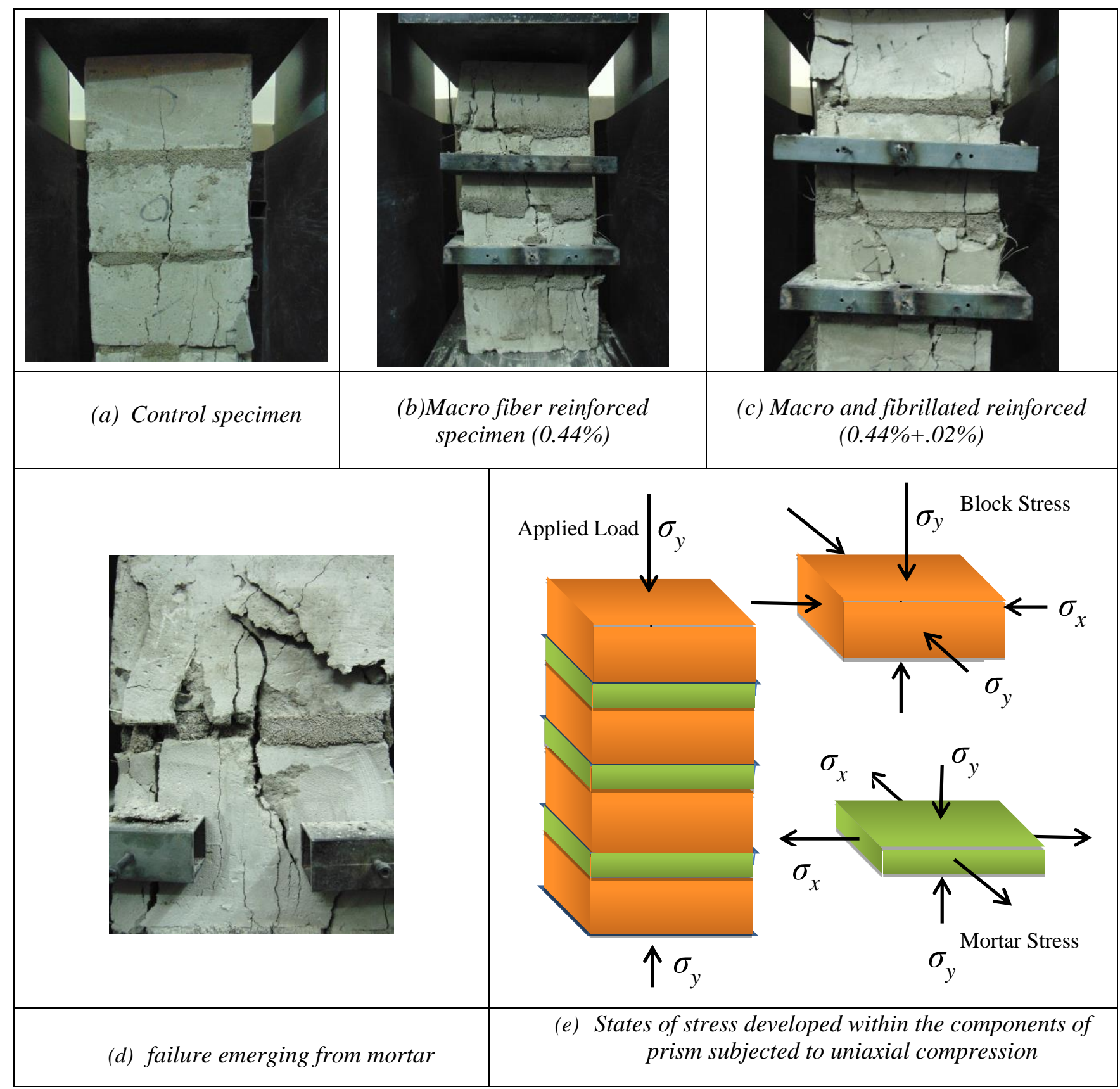

1

Fig. 10-Failure of Stack bonded prisms under Compression with and without Fibers 


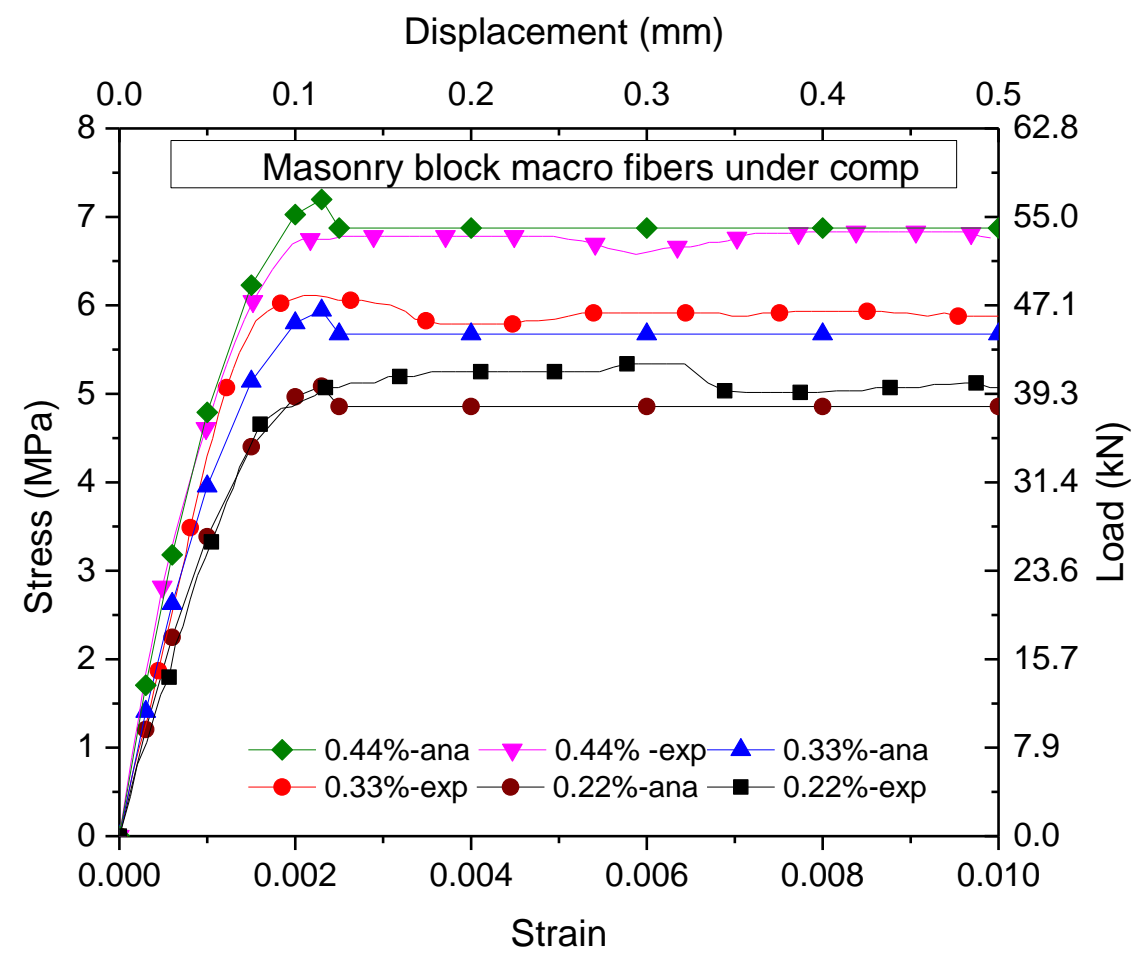

1

(a) Macro Fiber Reinforced CLC Cylinders Displacement (mm)

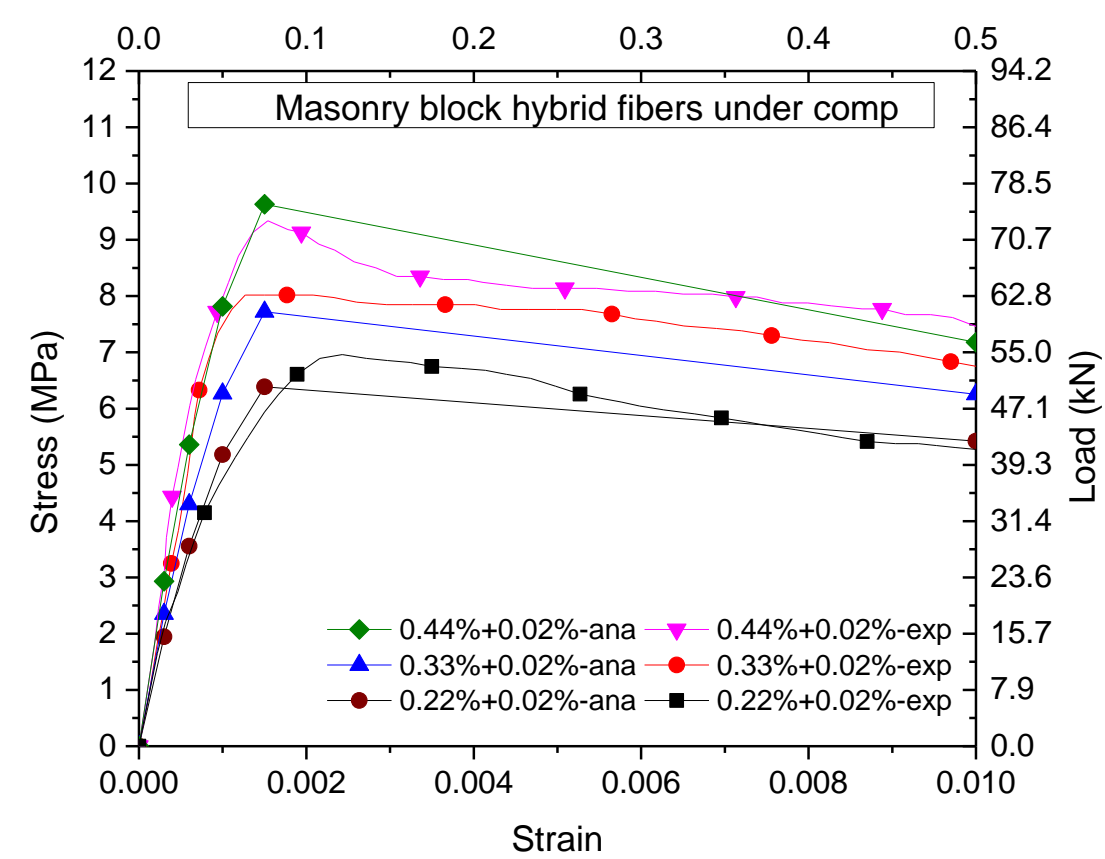

(b) Hybrid Fiber Reinforced CLC Cylinders

7 CLC Cylinders $(1 \mathrm{ksi}=7 \mathrm{MPa} ; 1 \mathrm{kip}=4.4 \mathrm{kN} ; 1$ in. $=25.4 \mathrm{~mm})$ 


\section{Displacement $(\mathrm{mm})$}

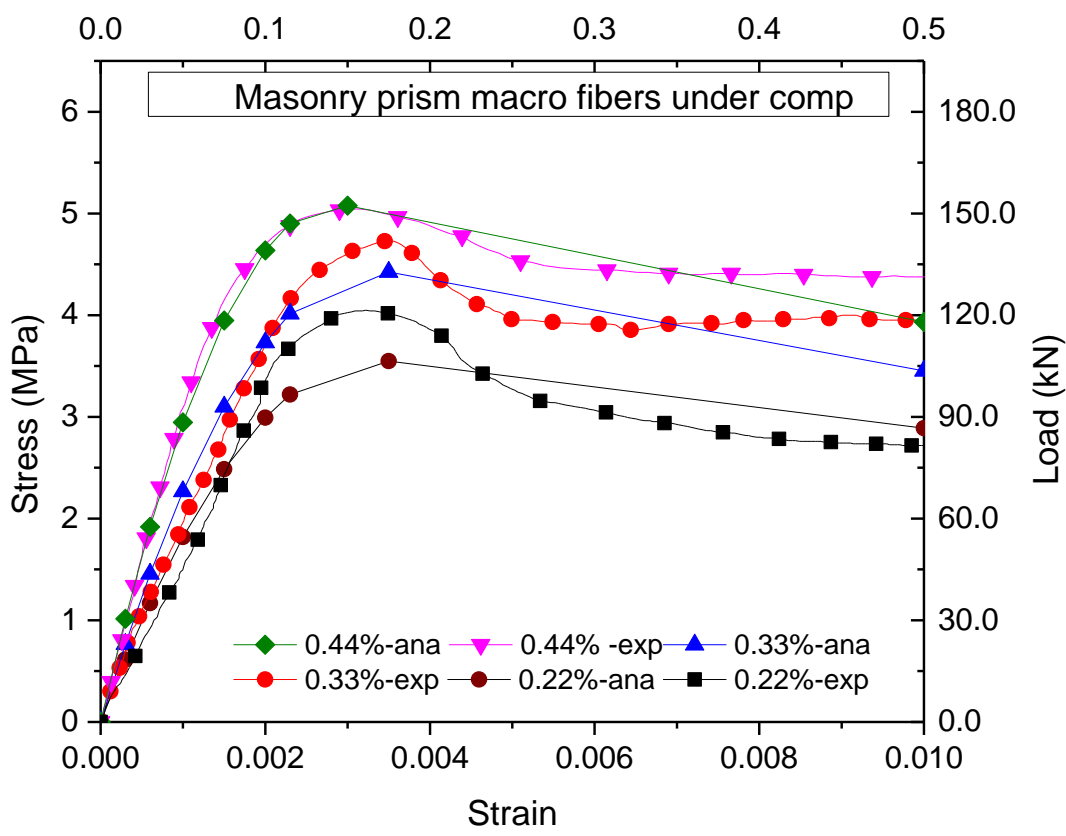

(a) Macro Fiber Reinforced Prisms

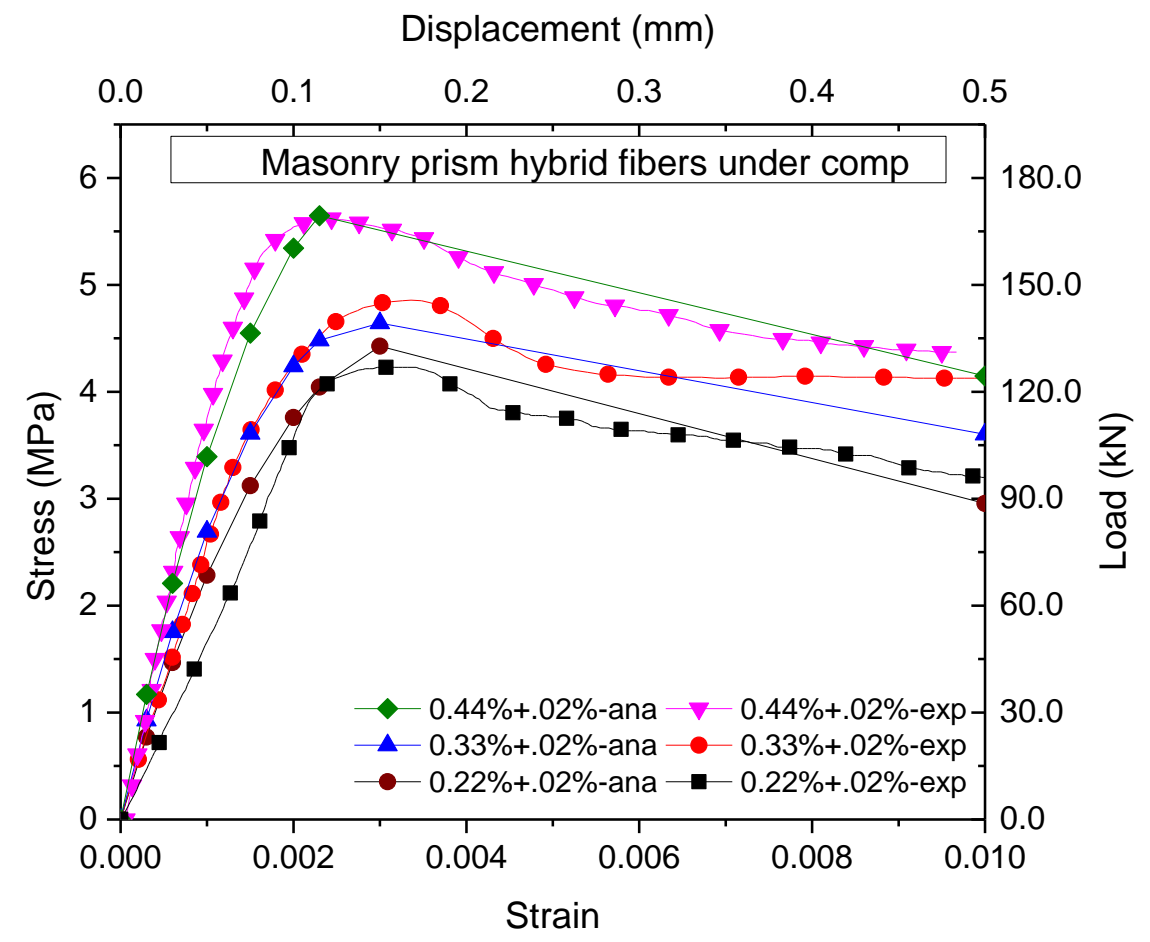

(b) Hybrid Fiber Reinforced Prisms

5 Fig. 12-Comparison of Analytical Stress-Strain Curve Predictions with Experimental Test

$6 \quad$ Results of Fiber Reinforced Prism $(1 \mathrm{ksi}=7 \mathrm{MPa} ; 1 \mathrm{kip}=4.4 \mathrm{kN} ; 1 \mathrm{in} .=25.4 \mathrm{~mm})$ 